\title{
Malicious Destruction of Plantation (MDOP) and 3D Footprint Identified the Perpetrator: A Rare Case Report
}

ISSN: 2578-0042

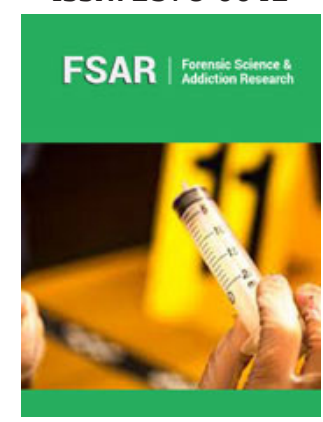

*Corresponding author: Nataraja Moorthy T, Associate Professor of Forensic Sciences, Management and Science University, Shah Alam, Selangor, Malaysia.

Email: natrajamoorthy@rediffmail.com; nataraajan64@msu.edu.my

Submission: 幽 February 15, 2019

Published: : March 25, 2019

Volume 4 - Issue 3

How to cite this article: Nataraja $M$ T. Malicious Destruction of Plantation (MDOP) and 3D Footprint Identified the Perpetrator: A Rare Case Report. Forensic Sci Add Res. 4(3). FSAR.000595.2019. DOI: 10.31031/FSAR.2019.04.000595

Copyright@ Nataraja Moorthy T, This article is distributed under the terms of the Creative Commons Attribution 4.0 International License, which permits unrestricted use and redistribution provided that the original author and source are credited.

\author{
Nataraja Moorthy T * \\ Faculty of Health and Life Sciences, Management \& Science University, Selangor, Malaysia
}

\begin{abstract}
Foot impressions, both 2D and 3D are valuable physical evidence found in crime scenes for person identification. Footprints are used to estimate stature, living body weight and gender. Some investigators underestimated the value of footprint evidence and ignored during evidence collection process. This case study presents a real crime scene investigation in India wherein an unknown person who have maliciously destructed the grape plantation by cutting the trunk of the grapevine plantation, belonged to a farmer in the village. The offender was identified through 3D footprints left in the plantation field. In the court trial, the Honourable Judge accepted the testimony of the footprint evidence and the case ended with conviction.
\end{abstract}

Keywords: Case report; Crime scene investigation; Malicious destruction; Plantation; 3D footprint

\section{Introduction}

The use of foot impression evidence in criminal investigations dates back to 1862 when Jessie McLachlan's footprint placed her at the scene of a woman's murder for which McLachlan was subsequently convicted [1]. Statistical analysis of footprint data collected Sergeant Kennedy has found "the odds of a chance match" for a footprint in the general population of is one in 1.27 billion [2]. Footprint analysis is considered as a biometric technique used to obtain multiple information in crime scenes [3]. Foot impressions are still found at crime scenes, since offenders often tend to remove their footwear either to avoid noise or to gain better grip in climbing walls, etc., while entering or exiting the crime scene [4]. The footprint provides the size dimensions of the foot's plantar surface actually touching the floor or hard surface, which produces a two-dimensional footprint impression. The foot outline provides the size parameters of the fleshed bare foot and also represents the boundaries of the foot's impression in soft soil, mud, or any other substance that produces a three-dimensional footprint impression [5]. Foot impressions can provide more information to the investigators than finger prints during crime scene investigation [6]. Footprints can be used to determine stature $[7,8]$, gender [9] and body weight $[10,11]$. Recently a scene of crime case study was reported wherein $2 \mathrm{D}$ crime scene footprint solved a disputed suspicious death of a woman who found partially hanged in her residence [12]. The present case report shows the identification of an offender who maliciously destroyed the grapevine plantation in a village and the fact was brought to light through 3D footprint found in the grapevine yard.

\section{Case Study}

It was alleged that somebody had cut all the trunks of grapevine plantation in a village (India) with malicious intention to destroy the crops and made property loss. The land owner lodged a complaint with police station to identify the perpetrator. A case was registered by the police and the Inspector of police requisitioned the service of forensic crime scene investigator, Mobile Forensic Science Laboratory and to visit the crime scene and assist the investigation. The field criminalist (the corresponding author while as Government field criminalist in India) visited and examined the crime scene, the grapevine yard as shown in Figure 1.

In grapevine farming, the climbing plants that produce grapes as its fruits with thin trunks and for stability, the farmers construct trellis so that the plant trunks grow high wards and 
spread on the top surface of trellis and the hanging bunch of fruits can be harvested. If the trunks are cut off, the fruit set is lost. Figure 1 shows a typical grape yard and scene of crime yard. The trunks of all young plantations were found cut maliciously with an intention to make total loss and the field criminalist noticed 3D footprints in wet soil areas (Figure 1).
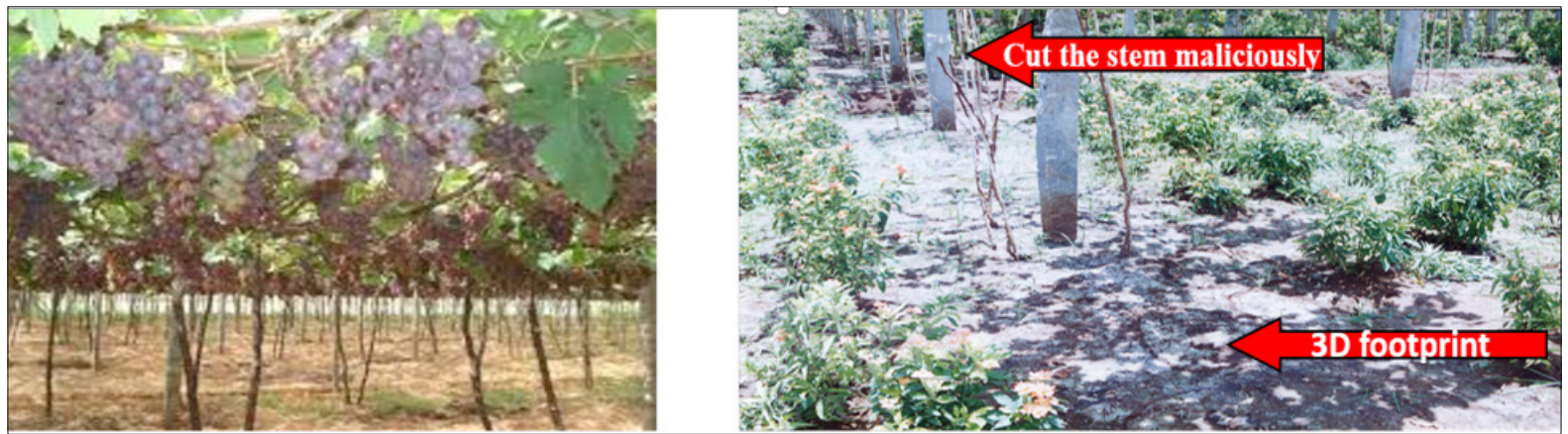

Figure 1: Typical grape yard and crime scene grape yard.

After thorough examination of the entire grape yard belonged to the complaint, the field criminalist finally chosen the 3D footprints suitable for sample collection and analysis. The field criminalist lifted the chosen 3D footprint by casting technique, as shown in Figure 2. While casting the 3D footprint was done in the crime site, many villagers assembled the area and watched the casting process along with the police inspector. The investigation revealed that one of the suspects was the owner of the neighbouring land, as alleged by the complainant, because of some motive. The footprint of the suspect was collected by the author in the scene of crime itself.
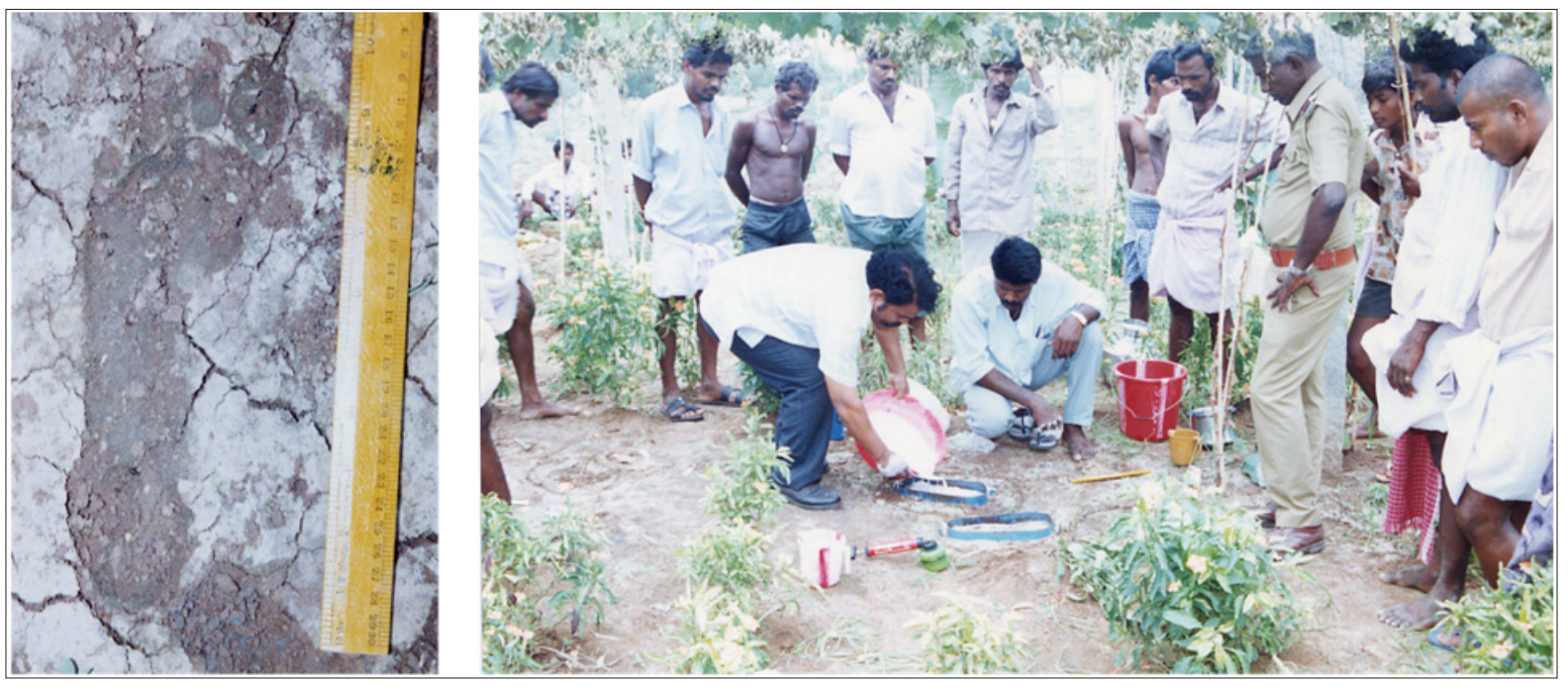

Figure 2: 3D footprint found on the land (left) and casting of $3 \mathrm{D}$ footprint in the crime scene (right). The Police Inspector and villagers are witnessing the casting process in the crime scene.

As the field criminalist (author) was a declared "Footprint Expert", the crime scene footprint and suspected footprint of the neighbouring field were compared, and the crime scene 3D footprint found tallied with the neighbouring landlord. The field criminalist finally opined that the offence was committed by neighboring landlord, based on 3D footprint. The field criminalist's opinion was recorded and submitted the crime scene report to the court. During trial, as a prosecution and expert witness, the field criminalist presented his testimony in the court of law. The Honorable judge accepted the value of footprint evidence and the case ended with conviction. Some of the investigators have underestimated the value of footprint evidence and neglected to collect this valuable physical evidence in the crime scenes [13].

\section{Conclusion}

The above case report in an example of Malicious Destruction of Property (MDOP), and the fact was identified by footprint evidence, a rare case report. In these incidences, the person who faces MDOP criminal charges is not a violent person but merely acted inappropriately or impulsively. Even in the property destruction incidences, footprint evidence may also play a vital role to the investigation and to arrive definite conclusion.

\section{References}

1. Judy hamilton (2013) Jessie McLachlan in Scotish murders: from Bruke and hare to Peter Tobin. Kindle edition, Waverly Scottish Classics, Glasgow, Scotland, USA. 
2. Kennedy RB, Chen S, Pressman IS, Yamashita AB, Pressman AE (2005) A large-scale statistical analysis of barefoot impressions. J Forensic Sci 50(5): 1071-1080.

3. Ambeth Kumar VD, Ramakrishnan M (2011) Legacy of footprint recognition - A review. Int J Computer Applicat 35(11): 9-16.

4. Nataraja Moorthy T, Mazida K, Hadzri M, Jayaprakash PT (2011) Estimation of stature based foot length of Malays in Malaysia. Aust J Forensic Sci 43(1): 13-26.

5. Robins LM (1986) Estimating height and weight from size of footprints. J Forensic Sci. 31(1): 143-152.

6. Nataraja Moorthy T, Hairunnisa MAK (2011) Sex determination from toeless Footprint among Ibans, An indigenous ethnic group in Malaysian Borneo. Forensic Sci Addi Res 3(5): 1-5.

7. Nataraja Moorthy T, Ang YL, Safee AS, Nik FH (2014) Estimation of stature from footprint and foot outline measurements in Malaysian Chinese. Australian J Forensic Sci 46(2): 136-159.
8. Nataraja Moorthy T, Rasvini A (2017) Determination of stature from dyanamic footprint anthropometry in Malaysian Malayalees for forensic investigation. J South Indi Medi Assoc 9 (1): 1-7.

9. Nataraja Moorthy T, Hairunnisa MAK (2018) Sex determination from footprint ridge density in Bidayuh population in Malaysian Borneo. Int J Med Tox Legal Med 21(3): 158-161.

10. Nataraja Moorthy T, Hairunnisa MAK (2017) Determination of body weight from footprint length measurements among Melanau population. Med Legal Update. 17(1): 249-254.

11. Nataraja Moorthy T, Hairunnisa MAK (2018) Body weight estimation from footprint length anthropometry in Lun Bawang ethnic of east Malaysia. Med Legal Update. 18(2): 164-169.

12. Nataraja Moorthy T (2019) Footprint evidence solved the mystery in a suspicious death: A rare case report. Peer Rev J Foren \& Gen Sci 3(2): 183-185.

13. Nataraja Moorthy T (2017) Neglected physical evidence during crime scene investigation. Foren Sci Add Res. 1(2): 1-2. 